\title{
Age dependency and modification of the Subarachnoid Hemorrhage Early Brain Edema Score
}

\author{
Michael Eibach, ${ }^{1}$ Sae-Yeon Won, MD, ${ }^{1}$ Markus Bruder, MD, ${ }^{1}$ Fee Keil, MD, ${ }^{2}$ Eva Herrmann, PhD, ${ }^{3}$ \\ Joachim Berkefeld, MD, PhD, ${ }^{2}$ Volker Seifert, MD, PhD, ${ }^{1}$ and Juergen Konczalla, MD, PhD'
}

\begin{abstract}
${ }^{1}$ Department of Neurosurgery, University Hospital Frankfurt, Goethe-University; ${ }^{2}$ Institute of Neuroradiology, University Hospital Frankfurt, Goethe-University; and ${ }^{3}$ nstitute of Biostatistics and Mathematical Modelling, Goethe-University, Frankfurt am Main, Germany
\end{abstract}

\begin{abstract}
OBJECTIVE The Subarachnoid Hemorrhage Early Brain Edema Score (SEBES) system measures cerebral edema on CT and can be used to predict outcome after subarachnoid hemorrhage (SAH). The authors developed a modified SEBES (SEBES 6c) and assessed whether it could predict outcome after SAH better than the SEBES. Furthermore, they verified the age dependency of these scores.
\end{abstract}

METHODS In this retrospective study, all patients with aneurysmal SAH in the period from January 2011 to February 2017 at a single institution were analyzed. The SEBES, which is based on the absence of visible sulci at two defined CT levels (0-4 points), and the SEBES $6 \mathrm{c}$ were determined from the initial CT. The SEBES $6 \mathrm{c}$ system includes the two levels from the original SEBES and one level located $2 \mathrm{~cm}$ below the vertex (0-6 points). The authors investigated whether the various SEBESs are age dependent and if they can predict delayed infarction (DI) and outcome.

RESULTS Two hundred sixty-one patients met the study inclusion criteria. The SEBES was an independent predictor for DI (OR 1.6 per 1-point increase) and unfavorable outcome (OR 1.36 per 1-point increase), in accordance with findings in the first publication on SEBES. However, here the authors found that the SEBES was age dependent. In the age group younger than 60 years, the patients with high-grade SEBESs (3-4 points) had DIs and unfavorable outcomes significantly more often than the patients with low-grade scores (0-2 points). In the age groups 60-69 years and $\geq 70$ years, no significant differences in DI and outcome were identified between high-grade and low-grade scores, although trends toward DI and unfavorable outcomes among the 60-69 age group were noted in patients with high-grade SEBESs.

Receiver operating characteristic curve analysis showed that SEBES $6 \mathrm{c}$ had a higher prognostic value in predicting outcome than SEBES ( $p$ < 0.001). Furthermore, SEBES $6 c$ predicted an unfavorable outcome (OR 1.31 per 1-point increase) and DI (OR 1.36 per 1-point increase) independent of vasospasms. SEBES $6 c$ showed an age dependency similar to that of SEBES.

CONCLUSIONS SEBES $6 \mathrm{c}$ is more suitable for predicting outcome after SAH than SEBES. Furthermore, it predicts outcome and DI independently of vasospasm, so it can be used to differentiate between early brain injury- and vasospasm-dependent infarctions and outcome. However, SEBES and SEBES $6 \mathrm{c}$ are both age dependent and can be used for patients aged $<60$ years and may have limited suitability for patients aged $60-69$ years and no suitability for patients aged $\geq 70$ years.

https://thejns.org/doi/abs/10.3171/2019.12.JNS192744

KEYWORDS subarachnoid hemorrhage; SEBES; delayed infarctions; outcome; age dependent; cerebral edema; vascular disorders

$\mathrm{S}$ UBARACHNOID hemorrhage (SAH) is a severe cerebrovascular disease with high mortality and morbidity. ${ }^{11,16,17}$ The most frequent causes of early death after $\mathrm{SAH}$ are direct effects of the initial bleeding, aneurysm rebleeding, and medical complications such as congestive heart failure. ${ }^{14}$ Another cause of poor outcomes in SAH is delayed cerebral ischemia (DCI).22,23 It was long believed that cerebral vasospasms (CVSs) are the main perpetrator of DCI. ${ }^{3,20}$ However, many investigations with the aim of reducing DCIs through the treatment of vasospasms,

ABBREVIATIONS AUC = area under the curve; CVS = cerebral vasospasm; $\mathrm{DCl}=$ delayed cerebral ischemia; $\mathrm{DI}=$ delayed infarction; $\mathrm{EBI}=$ early brain injury; $\mathrm{mRS}=$ modified Rankin Scale; ROC = receiver operating characteristic; SAH = subarachnoid hemorrhage; SEBES = Subarachnoid Hemorrhage Early Brain Edema Score; WFNS $=$ World Federation of Neurosurgical Societies. SUBMITTED October 8, 2019. ACCEPTED December 30, 2019.

INCLUDE WHEN CITING Published online March 20, 2020; DOI: 10.3171/2019.12.JNS192744. 
such as the CONSCIOUS-2 trial (Clazosentan in Reducing Vasospasm-related Morbidity and All-cause Mortality in Adult Patients With Aneurysmal Subarachnoid Hemorrhage Treated by Surgical Clipping) ${ }_{1}^{15}$ were unsuccessful, with the exception of the British aneurysm nimodipine trial. ${ }^{3,18,20,21}$

Therefore, recent research has focused more on early brain injury (EBI), 3,9,20 i.e., that occurring within the first 72 hours after SAH. Within the context of EBI, different processes, such as elevated intracranial pressure, cell death pathways, and inflammation, occur and can lead to DCI and a poor outcome. ${ }^{2,20}$ One key feature of EBI is cerebral edema. Different investigations have shown that cerebral edema is a risk factor for poor outcome. ${ }^{4,5}$ For a long time, however, no simple tool or score to measure cerebral edema was available. But then Ahn and colleagues created the Subarachnoid Hemorrhage Early Brain Edema Score (SEBES). ${ }^{1}$ The SEBES is a semiquantitative score that measures cerebral edema on cranial CT on the basis of two CT levels. In addition, the SEBES was identified as a predictor of DCI and poor outcome after SAH, but the results to date regarding the age dependency of the SEBES are inconsistent. ${ }^{1,19}$

We hypothesized that additional CT levels could improve the prognostic value of the SEBES. Therefore, the aim of our study was to verify, first, whether the SEBES and our modified SEBESs are applicable for all age groups and, second, if the several modified SEBESs can predict delayed cerebral infarctions and outcome better than the original SEBES.

\section{Methods \\ Study Population}

For our investigation, we retrospectively analyzed all patients with aneurysmal SAH who had been admitted to our hospital in the period from January 2011 to February 2017. Only patients with an initial CT within 24 hours after ictus were included. Patients with nonaneurysmal SAH, an initial CT later than 24 hours after ictus, or an age $<18$ years were excluded.

\section{CT Evaluation}

On the initial CT scan, we evaluated cerebral edema with the SEBES. The SEBES was assessed as described in the publication by Ahn et al. ${ }^{1}$ A SEBES of 3 or 4 points indicates severe cerebral edema (high-grade SEBES), whereas 2,1 , and 0 points indicate weak cerebral edema (low-grade SEBES). ${ }^{1}$

In addition, we used several modified SEBESs, referred to as "SEBES 6c" (cranial), "SEBES 6p" (posterior), and "SEBES 8" (cranial and posterior), to determine if other CT levels were more suitable to measure cerebral edema and could improve the validity of the SEBES.

SEBES 6c includes the two CT levels from the original SEBES system and one CT level located $2 \mathrm{~cm}$ below the vertex (Fig. 1A). One point is given for the absence of visible sulci at each level in each hemisphere, ${ }^{1,5}$ so the maximum point value is 6 . We defined $0-4$ points as low grade and 5-6 points as high grade.

SEBES 6p includes the levels from the original SEBES system and a CT level that shows an occipital sulcus (Fig. 1B). If this sulcus is not definable, 1 point is given for each hemisphere. The minimum value is 0 points and the maximum is 6 points; $0-4$ points were defined as low grade and 5-6 points as high grade.

SEBES 8 includes the CT levels from the original SEBES, SEBES 6c, and SEBES 6p, so the maximum score is 8 points ( $0-5$ points, low grade; $6-8$ points, high grade).

The SEBES, SEBES 6c, SEBES 6p, and SEBES 8 were determined by one blinded investigator, as done by Rass et al. because the interobserver reliability of the SEBES was high (Kappa value of 0.89) in the initial publication by Ahn and colleagues. ${ }^{1,19}$

Patient information, including age, sex, World Federation of Neurosurgical Societies (WFNS) grade, Fisher grade, and modified Rankin Scale (mRS) score 6 months after SAH, was taken from the medical records. Aneurysms were regularly treated within 24 hours after interdisciplinary consensus. ${ }^{13}$ Patient management has been described in detail elsewhere. ${ }^{12}$

Vasospasms were detected with transcranial Doppler ultrasonography, CTA, MRA, and/or digital subtraction angiography. Delayed infarction (DI) was defined as a new infarct on CT or MRI in comparison to initial imaging. Treatment-related infarctions were not defined as DI.

We stratified cohorts according to age: $<60$ years, 60 69 years, and $\geq 70$ years.

The local ethics committee of the University Hospital Frankfurt approved the study. Because the study design is retrospective, no written informed consent was necessary.

\section{Statistical Analysis}

Patients were stratified according to 6-month outcome (favorable: $\mathrm{mRS}$ score 0-2 vs unfavorable: mRS score 3-6). For nonparametric variables, the Wilcoxon-MannWhitney U-test was used, and for dichotomous variables, the chi-square test was used. Correlation between age and SEBES was calculated using the Spearman correlation. The prognostic ability of the different SEBESs was tested with a receiver operating characteristic (ROC) curve analysis. The predictive value of SEBES and SEBES 6c for an unfavorable outcome and DI was determined with multivariate stepwise logistic regression. A p value $<0.05$ was considered statistically significant. Statistical analysis was performed with BiAS for Windows (version 11.09, Epsilon Verlag).

\section{Results \\ Basic Characteristics}

A total of 668 patients were identified, and 261 patients met the study inclusion criteria. The main reasons for exclusion were an initial CT later than 24 hours after ictus and nonaneurysmal SAH. The mean patient age was 54.7 years (range 22-91 years), and 183 (70.1\%) of the 261 patients were women. Admission status was evaluated using the WFNS scale. On average, the WFNS grade was 3.3. The WFNS distribution for all patients is graphed in Supplemental Fig. 1. Only patients with an initial CT within 24 hours after ictus were included in the study, and the mean time to initial CT was 4.9 hours. Of the study patients, $78.9 \%$ had Fisher grade 3 or 4 SAH on initial CT. 
One hundred thirty-nine (53.3\%) patients were treated endovascularly, 92 (35.2\%) were treated with clipping, and $8(3.1 \%)$ were treated endovascularly and with clipping; 22 (8.4\%) patients were not treated. During their stay, $62.5 \%$ of the patients developed CVS and 114 (43.7\%) had DI. Six months after ictus, $51.3 \%$ of the patients had a favorable outcome (mRS score $0-2$ ) and $48.7 \%$ had an unfavorable outcome (mRS score 3-6); $21.8 \%$ of the patients died (Table 1).

\section{Validation of the SEBES}

The mean SEBES among all patients was 2.8, and $60.2 \%$ of the patients had a high-grade SEBES (3-4 points) and $39.8 \%$ had a low-grade SEBES (0-2 points). The complete distribution is shown in Fig. 1C.

In terms of patient sex, there was no difference between patients with a high-grade and those with a low-grade SEBES. However, patients with high-grade SEBESs were significantly younger (51.7 vs 59.2 years, $\mathrm{p}<0.001)$ than those with low-grade scores.

Admission status correlated with the SEBES. Patients with low-grade SEBESs had a significantly lower WFNS grade than the patients with high-grade scores (2.6 vs 3.8, $\mathrm{p}<0.001$; Table 1). On the initial CT, patients with highgrade SEBESs had Fisher grade 3 or 4 more often than the patients with low-grade SEBESs $(p=0.011)$. Aneurysms in patients with high-grade SEBESs were treated with clipping more frequently than aneurysms in the patients with low-grade SEBESs $(\mathrm{p}=0.006)$. More than half of all patients (62.5\%) developed CVS, but the patients with highgrade SEBESs developed vasospasms significantly more often $(70.7 \%$ vs $50 \%$, p < 0.001). Also, DIs were detected significantly more often in the patients with high-grade SEBESs $(\mathrm{p}<0.001)$. A favorable outcome was achieved in $43.3 \%$ of the patients with high-grade SEBESs compared to $63.5 \%$ of the patients with low-grade SEBESs (p $=0.002$ ). The mortality rate was higher in patients with high-grade SEBESs than in those with low-grade scores, but the difference was not significant (Table 1).

In accordance with these findings, a multivariate stepwise logistic regression showed that the SEBES is a predictor for DI (OR 1.6 per 1-point increase, 95\% CI 1.24$2.06, \mathrm{p}<0.001)$ and unfavorable outcome (OR 1.36 per 1-point increase, 95\% CI 1.03-1.8, $\mathrm{p}=0.032$ ), independent of WFNS grade, age, sex, and Fisher grade (Supplemental Table 1).

\section{Age Dependency of SEBES}

Between age and SEBES, there was a significant negative correlation, with a Spearman coefficient of $-0.35(\mathrm{p}<$ 0.001 ; Fig. 1D). In patients younger than 60 years of age, the mean SEBES was 3.1, and in those 60 and older, the mean SEBES was $2.2(\mathrm{p}<0.001)$. However, the admission status of older patients was worse than that of younger patients (Table 2), so admission status is not an explanation for the lower SEBESs in older patients.

Among patients younger than 60 years and those 70 or older, the patients with high-grade SEBESs had a significantly higher WFNS grade than the patients with lowgrade SEBESs. Also, among patients 60-69 years old, the
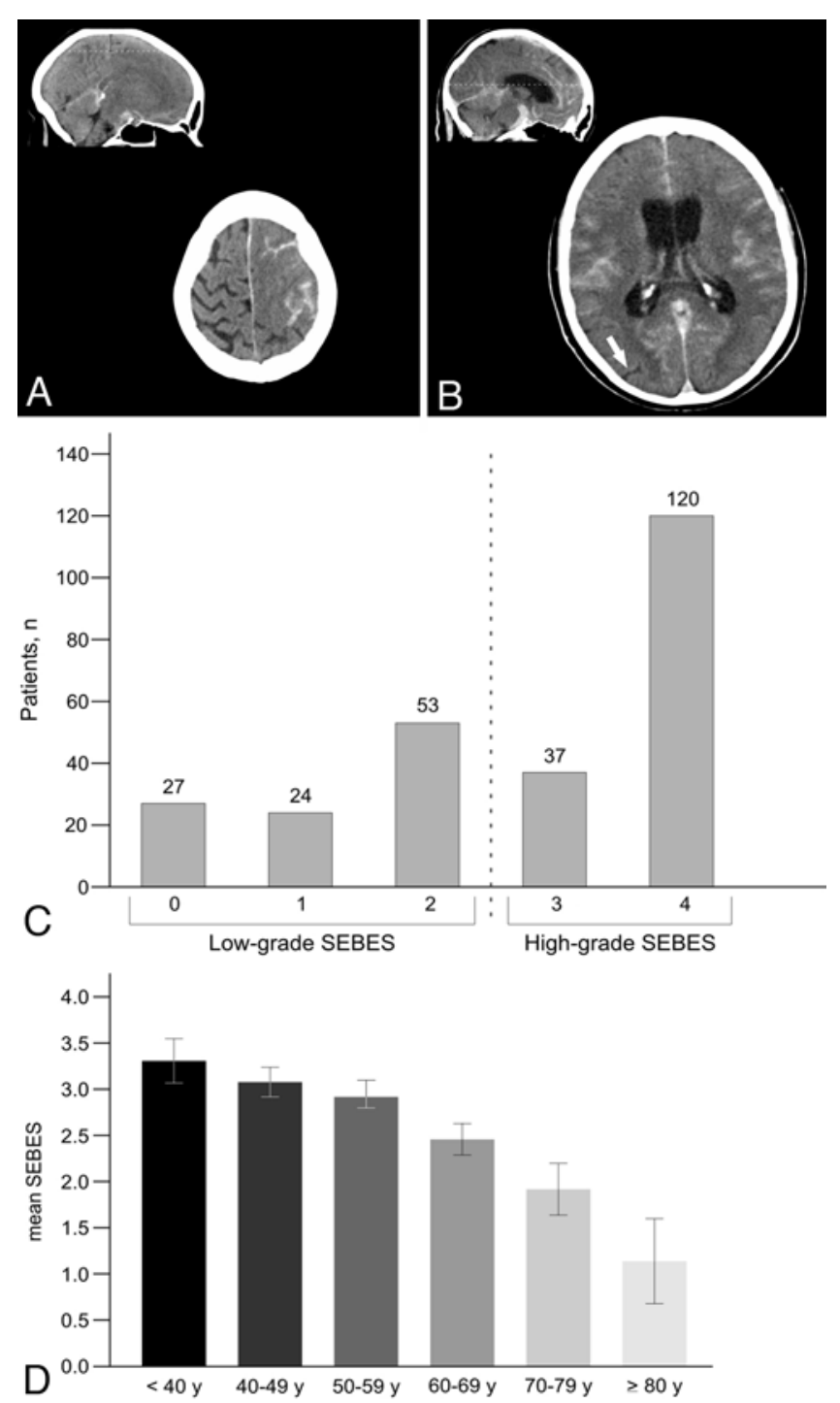

FIG. 1. The CT level $2 \mathrm{~cm}$ below the vertex (A) and at an occipital sulcus (arrow, B). Graphs showing the distribution of SEBESs in the study population (C; $x$-axis represents number of points) and the mean SEBESs in different age groups (D). Spearman correlation between SEBES and age $=-0.35, p<0.001 . n=$ number; $y=$ years .

WFNS grade was higher in those with high-grade SEBESs than in those with low-grade SEBESs (4 vs 3.1), but the difference between the two was not statistically significant $(\mathrm{p}=0.097)$. The occurrence of vasospasm was only associated with high-grade SEBESs in patients younger than 60 years of age. Moreover, exclusively in the age group younger than 60 years, those with high-grade SEBESs had DIs and unfavorable outcomes significantly more often than those with low-grade SEBESs. Among the age groups $60-69$ and $\geq 70$ years, there were no significant differences in DIs and unfavorable outcomes between those with lowgrade and those with high-grade SEBESs, although in the group 60-69 years old, there were trends toward DI and unfavorable outcome in those with high-grade SEBESs (DI: $44.8 \%$ vs $69 \%, \mathrm{p}=0.112$; favorable outcome: $55.2 \%$ vs $33.3 \%, \mathrm{p}=0.154$; Table 2). 
TABLE 1. Characteristics of patients and validation of SEBES

\begin{tabular}{lcccr}
\hline \multicolumn{1}{c}{ Variable } & All Patients & Low-Grade SEBES & High-Grade SEBES & $p$ Value \\
\hline No. of patients & 261 & $104(39.8)$ & $157(60.2)$ & \\
\hline Mean age in yrs & $54.7 \pm 12.7$ & $59.2 \pm 13$ & $51.7 \pm 11.6$ & $<0.001$ \\
\hline Female sex & $183(70.1)$ & $71(68.3)$ & $112(71.3)$ & 0.695 \\
\hline Mean WFNS grade & $3.3 \pm 1.7$ & $2.6 \pm 1.7$ & $3.8 \pm 1.6$ & $<0.001$ \\
\hline Mean time to initial CT in hrs & $4.9 \pm 4.8$ & $4.9 \pm 5.2$ & $4.9 \pm 4.6$ & 0.788 \\
\hline Fisher grade 3 or 4 & $206(78.9)$ & $70(67.3)$ & $136(86.6)$ & 0.011 \\
\hline Clipping & $92(35.2)$ & $28(26.9)$ & $64(40.8)$ & $0.006^{*}$ \\
\hline CVS & $163(62.5)$ & $52(50)$ & $111(70.7)$ & $<0.001$ \\
\hline DI & $114(43.7)$ & $31(29.8)$ & $83(52.9)$ & $<0.001$ \\
\hline Favorable outcome & $134(51.3)$ & $66(63.5)$ & $68(43.3)$ & 0.002 \\
\hline Mortality & $57(21.8)$ & $16(15.4)$ & $41(26.1)$ & 0.057 \\
\hline
\end{tabular}

Favorable outcome $=m R S$ score $\leq 2$. Values are expressed as number $(\%)$ or mean \pm standard deviation. The $p$ values were calculated with the Wilcoxon-Mann-Whitney U-test or chi-square test.

* Only clipping and coiling were considered: combined treatment and no treatment were not considered.

\section{Modified SEBESs}

Next, we determined if one of the modified SEBES systems (6c, 6p, and 8) was more suitable than the original SEBES for measuring cerebral edema and predicting outcome. For all modified systems (6c, 6p, and 8), the patients with high-grade scores had a significantly worse admission status and developed CVSs more often than patients with low-grade scores (Table 3). Moreover, patients with high-grade modified scores $(6 \mathrm{c}, 6 \mathrm{p}$, and 8$)$ had DIs and unfavorable outcomes more often than the patients with low-grade modified scores (Table 3). ROC curve analysis showed that SEBES 6c $(\mathrm{p}<0.001)$ and SEBES $8(\mathrm{p}=0.011)$ were significantly more suitable to predict outcome than SEBES and that SEBES 6p could not predict outcome better than SEBES (Fig. 2A). Multivariate stepwise logistic regression revealed that for SEBES 6c per 1-point increase, the OR for an unfavorable outcome was 1.31 (95\% CI 1.07-1.61) and for DI was 1.36 (95\% CI 1.13-1.63), independent of WFNS grade, age, sex, CVS, and Fisher grade (Table 4).

\section{Age Dependency of Modified SEBESs}

Like SEBES, all modified SEBESs (6c, 6p, and 8) showed a significant negative correlation with age (Supplemental Fig. 2). Furthermore, in all modified SEBESs, the rate of DI differed significantly between low-grade

TABLE 2. Different variables in low- and high-grade SEBESs, as related to age

\begin{tabular}{cccc}
\hline Variable & Low-Grade SEBES & High-Grade SEBES & p Value \\
\hline Mean WFNS & & & \\
\hline$<60$ yrs $(n=170)$ & $2.1 \pm 1.6$ & $3.6 \pm 1.6$ & $<0.001$ \\
\hline $60-69$ yrs $(n=59)$ & $3.1 \pm 1.8$ & $4.7 \pm 0.7$ & 0.097 \\
\hline$\geq 70$ yrs $(n=32)$ & $3.3 \pm 1.5$ & & 0.017 \\
\hline CVS & & 86 of $106(81.1)$ & $<0.001$ \\
\hline$<60$ yrs $(n=158)$ & 25 of $52(48.1)$ & 22 of $25(88.0)$ & 0.178 \\
\hline $60-69$ yrs $(n=54)$ & 20 of $29(69.0)$ & 3 of $6(50.0)$ & 1.0 \\
\hline$\geq 70$ yrs $(n=22)$ & 7 of $16(43.8)$ & & $<0$ of $112(51.8)$ \\
\hline DI & & 20 of $29(69.0)$ & 0.112 \\
\hline$<60$ yrs $(n=164)$ & 11 of $52(21.2)$ & 5 of $8(62.5)$ & 0.231 \\
\hline $60-69$ yrs $(n=58)$ & 13 of $29(44.8)$ & & $<0.001$ \\
\hline$\geq 70$ yrs $(n=28)$ & 7 of $20(35.0)$ & 56 of $118(47.5)$ & 0.154 \\
\hline Favorable outcome & & 10 of $30(33.3)$ & 1.0 \\
\hline$<60$ yrs $(n=170)$ & 45 of $52(86.5)$ & 2 of $9(22.2)$ & \\
\hline $60-69$ yrs $(n=59)$ & 16 of $29(55.2)$ & 5 of $23(21.7)$ & \\
\hline$\geq 70$ yrs $(n=32)$ & & & \\
\hline
\end{tabular}

Favorable outcome $=m R S$ score $\leq 2 ; n=$ number of cases. Values are expressed as number $(\%)$ or mean \pm standard deviation. The $p$ values were calculated with the Wilcoxon-Mann-Whitney U-test or chi-square test. 
TABLE 3. Modified SEBESs

\begin{tabular}{lccr}
\hline \multicolumn{1}{c}{ Variable } & $\begin{array}{c}\text { Low-Grade } \\
\text { Score }\end{array}$ & $\begin{array}{c}\text { High-Grade } \\
\text { Score }\end{array}$ & \multicolumn{1}{c}{$\begin{array}{c}\text { P } \\
\text { Value }\end{array}$} \\
\hline SEBES 6c & & & \\
\hline No. (\%) & $30(72.8)$ & $71(27.2)$ & \\
\hline Mean WFNS & 116 of $177(65.5)$ & 47 of $57(82.5)$ & 0.024 \\
\hline CVS & 71 of $185(38.4)$ & 43 of $65(66.2)$ & $<0.001$ \\
\hline DI & 112 of $190(58.9)$ & 22 of $71(31.0)$ & $<0.001$ \\
\hline Favorable outcome & & & \\
\hline SEBES 6p & $110(42.1)$ & $151(57.9)$ & \\
\hline No. (\%) & $2.7 \pm 1.7$ & $3.8 \pm 1.5$ & $<0.001$ \\
\hline Mean WFNS & 57 of $102(55.9)$ & 106 of $132(80.3)$ & $<0.001$ \\
\hline CVS & 35 of $107(32.7)$ & 79 of $143(55.2)$ & $<0.001$ \\
\hline DI & 70 of $110(63.6)$ & 64 of $151(42.4)$ & 0.001 \\
\hline Favorable outcome & & & \\
\hline SEBES 8 & $140(53.6)$ & $121(46.4)$ & \\
\hline No. (\%) & $2.8 \pm 1.7$ & $3.9 \pm 1.5$ & $<0.001$ \\
\hline Mean WFNS & 80 of $130(61.5)$ & 83 of $104(79.8)$ & 0.004 \\
\hline CVS & 50 of $137(36.5)$ & 64 of $113(56.6)$ & 0.002 \\
\hline DI & 86 of $140(61.4)$ & 48 of $121(39.7)$ & $<0.001$ \\
\hline Favorable outcome & & & \\
\hline Favable & & &
\end{tabular}

Favorable outcome $=m R S$ score $\leq 2$. Values are expressed as number $(\%)$ or mean \pm standard deviation. The $p$ values are calculated with the Wilcoxon-Mann-Whitney U-test or chi-square test.

and high-grade SEBESs among patients younger than 60 years of age but not in patients 60-69 years or $\geq 70$ years (Supplemental Table 2).

An ROC curve analysis indicated that in patients younger than 60 years, SEBES 6c (area under the curve [AUC] 0.776, p < 0.001) and SEBES 8 (AUC 0.78, p < $0.001)$ had a significantly higher prognostic value for the prediction of unfavorable outcome than SEBES (AUC 0.708 ; Fig. 2B). Furthermore, in a stepwise logistic regression analysis, SEBES 6c was a predictor for DI (OR 1.34 per 1-point increase, 95\% CI 1.05-1.72) and unfavorable outcome (OR 1.46 per 1-point increase, 95\% CI 1.12-1.9) in patients younger than 60 years, independent of WFNS grade, CVS, and Fisher grade. SEBES was only an independent predictor for unfavorable outcome (OR 1.6 per 1-point increase, 95\% CI 1.06-2.41), not for DI, in patients younger than 60 years of age (Supplemental Table 3).

Note, however, that none of the modified SEBESs could predict outcome significantly better than SEBES in patients ages 60-69 years or $\geq 70$ years (Fig. 2C and D).

\section{Discussion}

First, we validated the SEBES in our patient population and then compared it with the various modified SEBESs. Our results showed, congruent with the findings of Ahn et al., ${ }^{1}$ that SEBES correlates with WFNS grade at admission and predicts DI and poor outcome. Additionally, we showed that SEBES predicts outcome not only 3 months after $\mathrm{SAH}^{1}$ but also 6 months after SAH. According to our results, SEBES is an easy and valid tool to measure cerebral edema and predict outcome in patients with SAH.
However, we found that SEBES is age dependent given that the SEBES point value was significantly lower in older patients than in younger patients. A possible explanation for this finding could be age-related brain atrophy. ${ }^{8,10,19}$ Furthermore, Choi et al. reported on the quantitative measurement of cerebral edema based on sulcal volume and also identified an age dependency. ${ }^{4}$ In addition, we showed that outcome and the occurrence of DIs between low-grade and high-grade SEBESs differed significantly only among patients younger than 60 years of age. In a comparison between high-grade and low-grade SEBESs, we identified a trend toward DI and unfavorable outcome in the group that was 60-69 years and no differences in the patients with ages $\geq 70$ years. These results suggested that the SEBES is well suited for patients younger than 60 years, has limited suitability for patients who are 60-69 years old, and may not be suitable for patients with ages $\geq$ 70 years. It should be noted that the numbers of patients aged $60-69$ years and $\geq 70$ years were relatively low.

Moreover, we investigated possible modifications of SEBES. A high point value in each of the three modified SEBESs (SEBES 6c, 6p, and 8), like the SEBES, was associated with more DIs and poor outcomes 6 months after SAH . However, ROC curve analysis showed that SEBES 6c (AUC 0.654) predicts outcome better than SEBES and SEBES 6p (Fig. 2A). A possible explanation for this finding is that in cerebral edema, cranially located sulci may be the last to efface, and that a high point value in SEBES $6 c$ could be an indicator for maximum brain edema. So, SEBES 6c may differentiate the cerebral edema in patients with $\mathrm{SAH}$, especially those with a poor admission status, better than SEBES. A potential reason that SEBES $6 \mathrm{p}$ is not more suitable than SEBES for measuring cerebral edema may be that the investigated occipital sulcus is effaced in the majority of patients, so SEBES $6 p$ does not offer more differentiation.

SEBES 8 had a prognostic value like SEBES 6c, but we favor SEBES $6 c$ because it is more simple (not necessary to look for an occipital sulcus) and faster to score.

In addition, stepwise logistic regression showed that SEBES 6c predicts DI and outcome independent of WFNS grade and the occurrence of vasospasms. This indicates that SEBES $6 \mathrm{c}$ is not just a reflection of admission status. Moreover, these results suggest that CVS as well as brain edema, and thus EBI, is responsible for the higher number of DIs and unfavorable outcomes in patients with high-grade SEBES 6c. This is in accordance with the change from vasospasms to EBI in SAH research..$^{3,9,20}$ Furthermore, brain edema and CVS seem to be independent processes of a multifactorial disease leading to a poor outcome after SAH.

However, in patients younger than 60 years of age, SEBES, in contrast to SEBES 6c, only predicted unfavorable outcome, and not DI, independent of CVS. This is scientifically and clinically important because using the SEBES $6 c$ in further studies could differentiate between CVS- and EBI-related infarctions and outcome. So, we have a valid tool to measure brain edema, and thus EBI, in the future, and it may be possible to monitor new treatments for EBI and EBI-related infarctions.

In relation to age dependency, there were no significant 

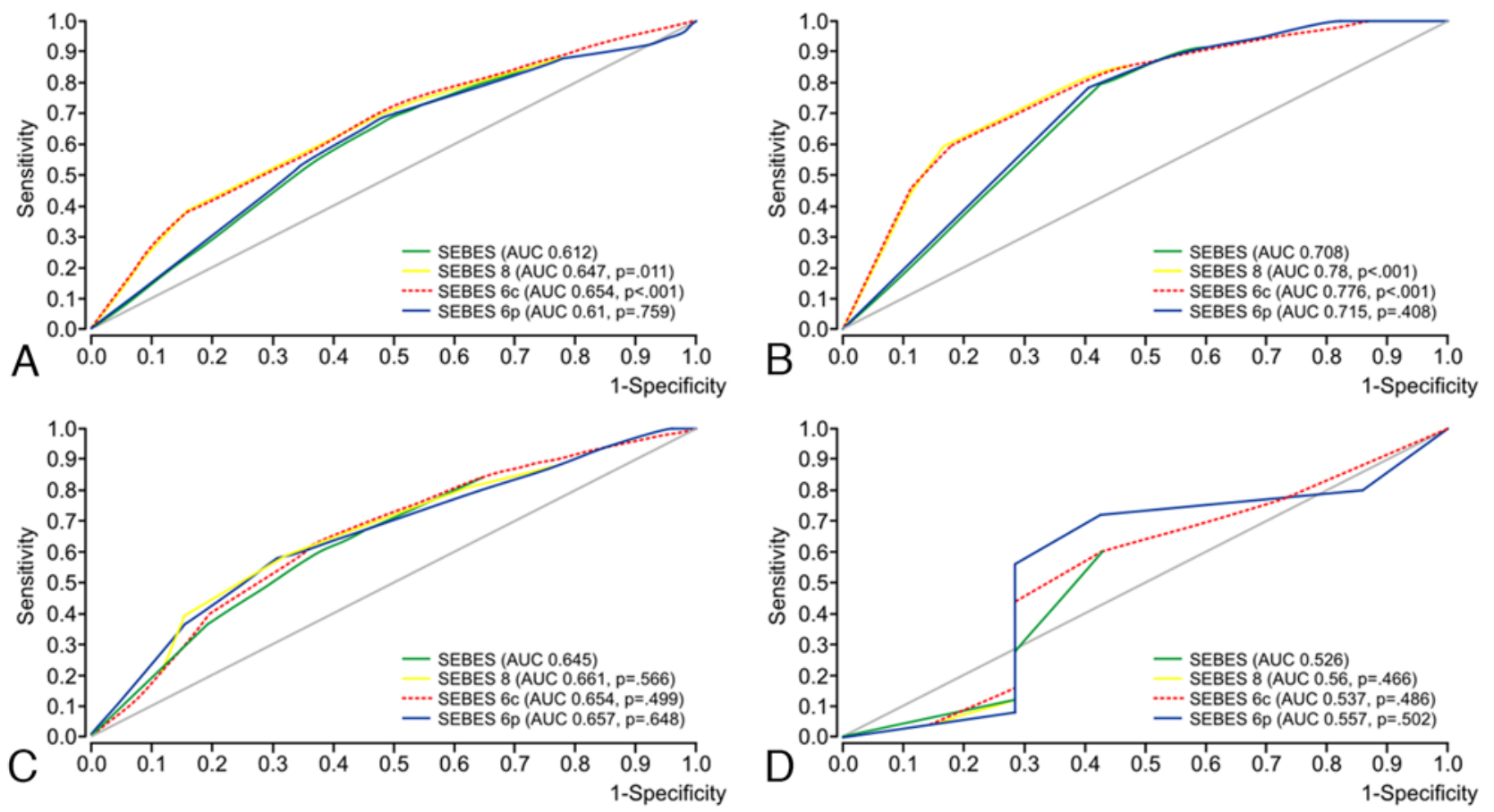

FIG. 2. ROC curve analyses were performed for the prediction of an unfavorable outcome ( $\mathrm{mRS}$ score $\geq 3$ ) relating to the original SEBES and modified SEBESs (SEBES 6c, 6p, and 8) in different age groups. The AUCs were calculated for the entire study population $(\mathbf{A})$ and for patients with ages $<60$ years $(\mathbf{B})$, ages $60-69$ years $(\mathbf{C})$, and ages $\geq 70$ years $(\mathbf{D})$. Figure is available in color online only.

differences between the various SEBESs. This suggests that SEBES 6c, like SEBES, is only partially suitable for patients aged 60-69 and may not be suitable for patients aged $\geq 70$ years. However, it is noteworthy that SEBES $6 \mathrm{c}$ had the highest prognostic value for predicting unfavorable outcome, with an AUC of 0.78 in patients younger than 60 years.

These data suggest that SEBES $6 c$ is also a suitable score to measure cerebral edema in patients with SAH and predicts outcome and DI better than SEBES even independent of CVS. However, SEBES $6 \mathrm{c}$ is only partially suitable for patients aged 60-69 and may not be suitable for patients aged $\geq 70$ years.

\section{Study Limitations}

A relevant limitation of our study was the retrospective single-center analysis with typical restrictions such as lack

TABLE 4. Odds ratios for SEBES $6 \mathrm{c}$ to predict DIs and unfavorable outcomes

\begin{tabular}{lcc}
\hline \multicolumn{1}{c}{ Variable } & OR $(95 \%$ Cl $)$ & p Value \\
\hline DI: SEBES 6c, per 1-point increase & $1.36(1.13-1.63)^{*}$ & 0.001 \\
\hline $\begin{array}{l}\text { Unfavorable outcome: SEBES 6c, per } \\
\text { 1-point increase }\end{array}$ & $1.31(1.07-1.61)^{*}$ & 0.01 \\
\hline
\end{tabular}

A stepwise logistic regression was performed to calculate the odds ratios for SEBES $6 \mathrm{c}$ to predict DI and unfavorable outcome (mRS score $\geq 3$ ).

* Adjusted for WFNS grade, CVS, age, sex, and Fisher grade. of data. The investigator of the CT scans was blinded to minimize bias. Another limitation was the relatively low number of older patients (60-69 years and $\geq 70$ years); thus, while the statement seems to be clear, the power of the statement regarding the age dependency of SEBES and modified SEBES is limited in patients aged $\geq 60$ years.

For the stated reasons, a prospective multicenter study to evaluate SEBES is desirable, especially as relates to SEBES 6c.

\section{Conclusions}

Our study showed that SEBES is suitable for measuring cerebral edema and predicting outcome in patients with SAH. However, it is remarkable that SEBES is only partially suitable for patients aged 60-69 and may not be suitable for patients aged $\geq 70$ years. Furthermore, we developed a modified SEBES, called "SEBES 6c." This score predicted DI and outcome better than SEBES, even independent of CVS. So, modifying the SEBES to SEBES $6 c$ could help to differentiate between EBI- and CVS-dependent DI and/or unfavorable outcome. However, SEBES $6 c$, like the SEBES, is age dependent. Thus, we suggest that SEBES 6c should be used to measure cerebral edema in patients younger than 60 years of age and needs to be validated for patients older than 60 years in a larger cohort.

\section{Acknowledgments}

We thank Marina Heibel and Anne Sicking for their excellent technical support. 


\section{References}

1. Ahn SH, Savarraj JP, Pervez M, Jones W, Park J, Jeon SB, et al: The Subarachnoid Hemorrhage Early Brain Edema Score predicts delayed cerebral ischemia and clinical outcomes. Neurosurgery 83:137-145, 2018

2. Cahill J, Calvert JW, Zhang JH: Mechanisms of early brain injury after subarachnoid hemorrhage. J Cereb Blood Flow Metab 26:1341-1353, 2006 (Erratum in J Cereb Blood Flow Metab 26:1463, 2006)

3. Caner B, Hou J, Altay O, Fujii M, Zhang JH: Transition of research focus from vasospasm to early brain injury after subarachnoid hemorrhage. J Neurochem 123 (Suppl 2):12-21, 2012

4. Choi HA, Bajgur SS, Jones WH, Savarraj JPJ, Ko SB, Edwards NJ, et al: Quantification of cerebral edema after subarachnoid hemorrhage. Neurocrit Care 25:64-70, 2016

5. Claassen J, Carhuapoma JR, Kreiter KT, Du EY, Connolly ES, Mayer SA: Global cerebral edema after subarachnoid hemorrhage: frequency, predictors, and impact on outcome. Stroke 33:1225-1232, 2002

6. Eibach M, Kashefiolasl S, Brawanski N, Bruder M, Herrmann E, Seifert V, et al: The modified Subarachnoid Hemorrhage Early Brain Edema Score (mSEBES), in 70. Jahrestagung der Deutschen Gesellschaft für Neurochirurgie (DGNC) Joint Meeting mit der Skandinavischen Gesellschaft für Neurochirurgie (Abstract) (https://www.egms. de/static/en/meetings/dgnc2019/19dgnc296.shtml) [Accessed January 17, 2020]

7. Eibach M, Won SY, Kashefiolasl S, Dinc N, Bruder M, Herrmann E, et al: Validation and age dependency of Subarachnoid Hemorrhage Early Brain Edema Score (SEBES), in $\mathbf{7 0 .}$ Jahrestagung der Deutschen Gesellschaft für Neurochirurgie (DGNC) Joint Meeting mit der Skandinavischen Gesellschaft für Neurochirurgie (Abstract) (https:// www.egms.de/static/en/meetings/dgnc2019/19dgnc295.shtml) [Accessed January 17, 2020]

8. Esiri MM: Ageing and the brain. J Pathol 211:181-187, 2007

9. Fujii M, Yan J, Rolland WB, Soejima Y, Caner B, Zhang JH: Early brain injury, an evolving frontier in subarachnoid hemorrhage research. Transl Stroke Res 4:432-446, 2013

10. Jin K, Zhang T, Shaw M, Sachdev P, Cherbuin N: Relationship between sulcal characteristics and brain aging. Front Aging Neurosci 10:339, 2018

11. Johnston SC, Selvin S, Gress DR: The burden, trends, and demographics of mortality from subarachnoid hemorrhage. Neurology 50:1413-1418, 1998

12. Konczalla J, Brawanski N, Bruder M, Senft C, Platz J, Seifert $\mathrm{V}$ : Outcome of patients with long-lasting cerebral vasospasm after subarachnoid hemorrhage: is prolonged treatment for cerebral vasospasm worthwhile? A matched-pair analysis. World Neurosurg 88:488-496, 2016

13. Konczalla J, Seifert V, Beck J, Güresir E, Vatter H, Raabe A, et al: Outcome after Hunt and Hess Grade V subarachnoid hemorrhage: a comparison of pre-coiling era (1980-1995) versus post-ISAT era (2005-2014). J Neurosurg 128:100110,2018

14. Lantigua H, Ortega-Gutierrez S, Schmidt JM, Lee K, Badjatia N, Agarwal S, et al: Subarachnoid hemorrhage: who dies, and why? Crit Care 19:309, 2015

15. Macdonald RL, Higashida RT, Keller E, Mayer SA, Molyneux A, Raabe A, et al: Clazosentan, an endothelin receptor antagonist, in patients with aneurysmal subarachnoid haemorrhage undergoing surgical clipping: a randomised, doubleblind, placebo-controlled phase 3 trial (CONSCIOUS-2). Lancet Neurol 10:618-625, 2011
16. Macdonald RL, Schweizer TA: Spontaneous subarachnoid haemorrhage. Lancet 389:655-666, 2017

17. Nieuwkamp DJ, Setz LE, Algra A, Linn FHH, de Rooij NK, Rinkel GJE: Changes in case fatality of aneurysmal subarachnoid haemorrhage over time, according to age, sex, and region: a meta-analysis. Lancet Neurol 8:635-642, 2009

18. Pickard JD, Murray GD, Illingworth R, Shaw MD, Teasdale GM, Foy PM, et al: Effect of oral nimodipine on cerebral infarction and outcome after subarachnoid haemorrhage: British aneurysm nimodipine trial. BMJ 298:636-642, 1989

19. Rass V, Ianosi BA, Wegmann A, Gaasch M, Schiefecker AJ, Kofler M, et al: Delayed resolution of cerebral edema is associated with poor outcome after nontraumatic subarachnoid hemorrhage. Stroke 50:828-836, 2019

20. Sehba FA, Pluta RM, Zhang JH: Metamorphosis of subarachnoid hemorrhage research: from delayed vasospasm to early brain injury. Mol Neurobiol 43:27-40, 2011

21. Velat GJ, Kimball MM, Mocco JD, Hoh BL: Vasospasm after aneurysmal subarachnoid hemorrhage: review of randomized controlled trials and meta-analyses in the literature. World Neurosurg 76:446-454, 2011

22. Vergouwen MDI: Vasospasm versus delayed cerebral ischemia as an outcome event in clinical trials and observational studies. Neurocrit Care 15:308-311, 2011

23. Vergouwen MDI, Vermeulen M, van Gijn J, Rinkel GJE, Wijdicks EF, Muizelaar JP, et al: Definition of delayed cerebral ischemia after aneurysmal subarachnoid hemorrhage as an outcome event in clinical trials and observational studies: proposal of a multidisciplinary research group. Stroke 41:2391-2395, 2010

\section{Disclosures}

The authors report no conflict of interest concerning the materials or methods used in this study or the findings specified in this paper.

\section{Author Contributions}

Conception and design: Eibach, Konczalla. Acquisition of data: Eibach, Won, Konczalla. Analysis and interpretation of data: Eibach, Konczalla. Drafting the article: Eibach, Won. Critically revising the article: Eibach, Won, Bruder, Keil, Berkefeld, Seifert, Konczalla. Reviewed submitted version of manuscript: all authors. Statistical analysis: Eibach, Herrmann. Study supervision: Konczalla.

\section{Supplemental Information \\ Online-Only Content}

Supplemental material is available with the online version of the article.

Supplemental Figures and Tables. https://thejns.org/doi/suppl/ 10.3171/2019.12.JNS192744.

\section{Previous Presentations}

Portions of this work were presented as part of a lecture and published as abstracts ${ }^{6,7}$ at the Annual Meeting of the German Society of Neurosurgery (DGNC) held in Würzburg, Germany, on May 15, 2019.

\section{Correspondence}

Michael Eibach: Goethe-University, Frankfurt am Main, Germany.michael.eibach@kgu.de. 